\title{
GÊNESE DE HORIZONTE COESO, FRAGIPÃ E DURIPÃ EM SOLOS DO TABULEIRO COSTEIRO DO SUL DA BAHIA ${ }^{(1)}$
}

\author{
Ana Maria Souza dos Santos Moreau ${ }^{(2)}$, Liovando Marciano da $\operatorname{Costa}^{(3)}$, \\ João Carlos Ker ${ }^{(3)}$, \& Felipe Haenel Gomes ${ }^{(4)}$
}

\begin{abstract}
RESUMO
A gênese de horizontes coesos em solos tem explicações não consistentes e, em muitos casos, contraditórias. Objetivou-se avaliar, em solos dos tabuleiros costeiros, os possíveis mecanismos físicos, químicos e mineralógicos que ocasionam o endurecimento em horizonte coeso, fragipã e duripã. Para isso, coletaram-se amostras de solos em duas toposseqüências. Na primeira, foram reconhecidas as classes Latossolo Vermelho eutrófico argissólico e Argissolo Amarelo distrófico latossólico e, na segunda, Argissolos Amarelo abrúptico e típico, e Espodossolo Cárbico órtico dúrico. As análises químicas consistiram da extração de $\mathrm{Fe}, \mathrm{Si}$ e $\mathrm{Al}$ com ditionito-citrato-bicarbonato de sódio e oxalato ácido de amônio. A mineralogia da fração argila foi avaliada por difratometria de raios-X. Os teores de $\mathrm{Fe}$, Si e $\mathrm{Al}$ recuperados com o ditionito e com o oxalato foram bastante baixos nos solos com presença de horizonte coeso. Por outro lado, no solo com fragipã e duripã, os teores de Si e Al do oxalato foram elevados, indicando a participação desses elementos como agentes cimentantes. A fração argila dos Argissolos é predominantemente caulinítica, sendo registrada a gibbsita apenas nos horizontes $\mathrm{Bt}_{1}, \mathrm{Bt}_{2}$ e $\mathrm{Bw}$ do Argissolo Amarelo latossólico. Para o solo com fragipã e duripã (Espodossolo Cárbico órtico dúrico), identificou-se a presença de gibbsita, e, apesar de ser a gibbsita considerada como desorganizadora do ajuste entre as lâminas de caulinita, a manifestação de endurecimento foi mantida. Assim, os mecanismos de endurecimento parecem distintos para horizonte coeso, fragipã e duripã.
\end{abstract}

Termos de indexação: camadas endurecidas, agente cimentante, sílica, aluminosilicato.

\footnotetext{
(1) Parte da Tese de Doutorado do primeiro autor, apresentada à Universidade Federal de Viçosa - UFV. Realizada com apoio financeiro da FAPEMIG e VERACEL Celulose. Recebido para publicação em maio de 2004 e aprovado em novembro de 2006.

(2) Professora Adjunta do Departamento de Ciências Agrárias e Ambientais da Universidade Estadual de Santa Cruz - UESC, Km 16, Rodovia Ilhéus/Itabuna, CEP 45650-000 Ilhéus (BA). E-mail: amoreau@uesc.br

(3) Professor do Departamento de Solos da Universidade Federal de Viçosa - UFV. CEP 36571-000 Viçosa (MG). Bolsistas do CNPq. E-mails: liovandomc@yahoo.com.br; jcker@ufv.br

(4) Doutorando em Agronomia, Escola Superior de Agricultura "Luiz de Queiroz" - ESALQ. Caixa Postal 09, CEP 13418-900 Piracicaba (SP). E-mail: felipehgomes@yahoo.com
} 


\title{
SUMMARY: GENESIS OF HARDENED HORIZONS, FRAGIPANANDDURIPAN IN SOILS OF THE COASTAL TABLELANDS OF SOUTH BAHIA
}

\begin{abstract}
The genesis of cohesive horizons in some soils is not well known yet and, in many cases, it is conflicting. The purpose of this study was to evaluate physical, chemical and mineralogical mechanisms that cause hardening in soils with cohesive horizons, fragipan and duripan in Brazilian Coastal Plain soils. Soil samples of two toposequences were sampled and the taxonomic classes of the soils were identified as Argisolic Eutrophic Red Latosol, Latosolic Dystrophic Yellow Argisol for the first toposequence, and Abruptic Dystrophic Yellow Argisol, Dystrophic Typic Yellow Argisol and Duric Orthic Carbic Spodosol, for the second sequence. The chemical analysis performed were $\mathrm{Fe}, \mathrm{Si}$, and Al extraction with sodium dithionite-citrate-bicarbonate $(D C B)$ and ammonium oxalate. The clay fraction mineralogy was evaluated by $X$-ray diffraction. Soils with cohesive horizons presented very low $\mathrm{Fe}$, Si, and Al contents extracted with both DCB and oxalate. Nevertheless, soil with fragipan and duripan showed high Si and Al content extracted with oxalate, indicating their role as cementing agents. The Argisol clay fraction is predominantly kaolinitic, and gibbsite was only found in the $B t_{1}, B t_{2}$ and $B w$ horizons of the Latosolic Yellow Argisol. Gibbsite was found in soils with fragipan and duripan (Duric Orthic Carbic Spodosol), and despite being considered a disorganizing agent of kaolinite adjustment, the hardpan characteristics were maintained. Thus, the hardening mechanisms of these soils seem different for cohesive, fragipan and duripan horizons.
\end{abstract}

Index terms: hardened layers, cementing agent, silicon, aluminum-silicate.

\section{INTRODUÇÃO}

Horizontes ou camadas endurecidas e fortemente adensadas são designadas como "pãs" ou "pans". Enquadram-se, nesta categoria, os fragipãs e duripãs (Winters \& Simonson, 1951; Jacomine, 1974), em que o efeito cimentante de elementos químicos como $\mathrm{Si}$, $\mathrm{Al}$ e Fe parece ter papel efetivo na sua gênese (Winters, 1942; Steinhardt \& Franzmeier, 1979; Karathanasis, 1987; Rolim Neto \& Santos, 1994; Filizola et al., 2001). No Brasil, Argissolos e Latossolos Amarelos dos tabuleiros costeiros da região litorânea apresentam horizontes endurecidos (horizonte BA e parte do Bt ou do Bw), quando secos. Apesar de se enquadrarem na definição de "pã”, não parecem ter na cimentação química a causa de sua formação (Achá Panoso, 1976; Anjos, 1985), embora trabalhos mais recentes indiquem também a participação de agentes cimentantes (Araújo Filho et al., 2001; Filizola et al., 2001; Romero et al., 2003; Nunes et al., 2003; Lima et al., 2004).

"Horizonte coeso" é uma terminologia utilizada para designar um estado de coesão manifestado quando o solo está seco, que desaparece ou torna-se bem menos expressivo quando o solo está úmido. Esta coesão é genética e comum em horizontes subsuperficiais de Latossolos e Argissolos Amarelos dos platôs litorâneos brasileiros, ocorrendo, em geral, na transição entre os horizontes A e B, podendo ocupar boa parte do B (Achá Panoso, 1976; Fonseca, 1986).

Sobre a gênese da coesão, hipóteses, tais como: preenchimento de microporos por argila e matéria orgânica iluviada (Achá Panoso, 1976; Fonseca, 1986); obstrução de poros por sílica (Nunes et al., 2003); baixo teor de $\mathrm{Fe}_{2} \mathrm{O}_{3}$ (Achá Panoso, 1976) e processos geomórficos em detrimento aos pedogenéticos (Anjos, 1985), têm sido levantadas desde a década de sessenta.

Pelo fato de o endurecimento do horizonte coeso manifestar-se quando o solo está seco, desaparecendo ou atenuando-se quando úmido, a Universidade Federal de Viçosa (1984) propõe seja o endurecimento em solos de tabuleiro originado de possível ajuste entre as partículas do solo, principalmente a caulinita, pela sua forma laminar e boa cristalinidade nestes ambientes.

Pelo visto, conclui-se que sobre gênese dos horizontes coesos existem várias tentativas de explicação, às vezes contraditórias. Isso indica que algumas ações de pesquisa são ainda perfeitamente pertinentes, sobretudo no que se refere à ação de elementos químicos na coesão, avaliada pelo uso de diferentes extratores químicos.

Além de horizonte coeso, duas outras feições morfológicas são encontradas nos solos dos tabuleiros costeiros, fragipã e duripã, sendo estes mais freqüentes nas áreas deprimidas da paisagem.

Fragipã é conceituado como um horizonte subsuperficial, com conteúdo baixo de matéria orgânica, aparentemente cimentado, alta densidade do solo, com consistência dura a muito dura, quando seco, e, quando molhado, apresenta-se quebradiço (Embrapa, 1999). Quanto à textura do horizonte, estes autores mencionam que é dominantemente média e arenosa e raramente argilosa. 
A natureza compacta e o comportamento quebradiço, quando úmido, dos fragipãs, restringindo parcialmente a penetração de água e raízes, são explicados por empacotamento cerrado (Petersen et al., 1970; Richie et al., 1974); pontes de argila (Grossman \& Cline, 1957) e, ou, ligação com um composto amorfo (Winters, 1942; Steinhardt \& Franzmeier, 1979; Karathanasis, 1987; Rolim Neto \& Santos, 1994; Filizola et al., 2001).

Segundo Franzmeier et al. (1989), dentre os agentes cimentantes, a sílica é o que tem recebido mais destaque na literatura. Além da sílica, alguns autores citam a participação também do $\mathrm{Al}$ (Anderson \& White, 1958; Nettleton et al., 1968; Filizola et al., 2001), como agente cimentante.

Fragipã e duripã diferenciam-se quanto ao grau de coesão, avaliado pela dureza e capacidade de fragmentação do material quando imerso em água. No fragipã, o fragmento seco torna-se menos resistente quando imerso em água, podendo desenvolver fraturas, com ou sem desprendimento de pedaços, e se esboroa em curto espaço de tempo. No duripã, a cimentação é suficientemente forte, de modo que fragmentos secos não se esboroam, mesmo durante prolongado período de umedecimento.

Embora os dados de pesquisa apontem a sílica como agente cimentante para os duripãs, Rodrigues Silva \& Leprun (1997), estudando esta feição em solos dos tabuleiros costeiros do nordeste brasileiro, constataram que o $\mathrm{Al}$ está presente na proporção de 3 para 1, em relação à sílica, podendo constituir-se em importante agente cimentante, considerando a quantidade fator tão importante quanto a efetividade na cimentação. Constatações similares foram feitas por Romero et al. ( 2003), em solos dos Tabuleiros Costeiro do litoral norte da Bahia.

Embora já se tenha discutido bastante o papel da sílica na cimentação de horizontes do tipo fragipã e duripã, alguns autores (Nunes et al., 2003) levantam a possibilidade de tal mecanismo atuar, expressandose, porém de forma menos intensa no horizonte coeso, necessitando esta hipótese de mais investigações.

Diante do exposto, o presente trabalho teve como objetivo avaliar os possíveis mecanismos físicos, químicos e mineralógicos que ocasionam o endurecimento dos horizonte coesos de Argissolos Amarelos, bem como a pedocimentação mais consistente e pouco variável com a umidade em solo com fragipã e duripã, desenvolvidos de sedimentos do Grupo Barreiras.

\section{MATERIAL E MÉTODOS}

Foram descritos e coletados cinco perfis de solos (Lemos \& Santos, 1996) desenvolvidos a partir de sedimentos argilo-arenosos do Grupo Barreiras e de rochas do embasamento cristalino que afloram nos Tabuleiros Costeiros. Os solos das duas toposseqüências estudadas localizam-se entre os paralelos $16^{\circ} 00^{\prime}$ ' $16^{\circ} 30^{\prime}$ 'S e os meridianos $39^{\circ} 20^{\prime}$ e $40^{\circ} 00^{\prime} \mathrm{W}$. Gr, nos municípios de Eunápolis e Itagimirim, no sul da Bahia. Na primeira toposseqüência, foram reconhecidas as classes Latossolo Vermelho (desenvolvido a partir de gnaisses melanocráticos do Pré-Cambriano, não inumados pelos sedimentos do Barreiras) e Argissolo Amarelo latossólico e, na segunda, Argissolo Amarelo abrúptico e típico e solo com presença de fragipã no horizonte E/ Bhsx, sobreposto a um duripã contínuo (Bhsm), classificado como Espodossolo Cárbico órtico dúrico.

A área dos solos estudados insere-se no domínio morfoestrutural dos Piemontes Costeiros, que se caracterizam por feições predominantemente conservadas, com interflúvios tabulares, representados pela unidade geomorfológica denominada Tabuleiros Costeiros, o que corresponde aos baixos platôs costeiros do Terciário e coberturas sobre o Pré-Cambriano. São superfícies tabulares, recortadas por vales relativamente profundos que guardam certo paralelismo entre si. De acordo com a classificação de Köppen, a região apresenta tipo climático Am, quente e úmido, com pequena estação seca, temperaturas elevadas de 25 a $27^{\circ} \mathrm{C}$, e índice pluviométrico elevado. A vegetação primária original era do tipo Floresta Tropical Subperenifólia, hoje com uso atual local de eucalipto, pastagem, mamão, remanescente florestal e mata secundária.

A partir de informações contidas no levantamento de solos da Veracel Celulose, e após percorrer intensamente a área, os solos foram selecionados e examinados. O material coletado foi seco ao ar, destorroado e peneirado em malha de $2 \mathrm{~mm}$, a fim de se obter a terra fina seca ao ar (TFSA), que foi submetida às análises químicas e mineralógicas descritas, sucintamente, a seguir.

As formas de Fe de melhor e pior cristalinidade foram avaliadas pelo método do ditionito-citratobicarbonato de sódio (DCB) (Mehra \& Jackson, 1960); e do oxalato ácido de amônio $0,2 \mathrm{~mol} \mathrm{~L}^{-1}, \mathrm{pH} 3,0$, no escuro (Mckeague \& Day, 1966), respectivamente. Também, nestes extratos, determinaram-se os teores de Si, por colorimetria (Franzmeier et al., 1984), e de $\mathrm{Al}$, por espectrofotometria de absorção atômica.

Para a análise mineralógica, utilizou-se a difratometria de raios-X na fração argila, após dispersão com $\mathrm{NaOH} 0,1 \mathrm{~mol} \mathrm{~L}^{-1}$. As amostras foram preparadas em lâminas de vidro e orientadas. Houve tratamento prévio com ditionito-citrato-bicarbonato de sódio para remoção dos óxidos de Fe (Mehra \& Jackson, 1960).

\section{RESULTADOS E DISCUSSÃO}

\section{Ferro, silício e alumínio extraídos pelo ditionito- citrato-bicarbonato e pelo oxalato de amônio}

De modo geral, os solos dos tabuleiros costeiros estudados apresentaram baixos teores de $\mathrm{Fe}_{2} \mathrm{O}_{3}$, 
extraídos pelo ditionito-citrato-bicarbonato (Quadro 1), considerando o baixo teor desses óxidos no próprio material de origem. Tomando apenas a primeira extração com DCB, percebe-se que a relação Feo/Fed foi mais elevada no Espodossolo Cárbico órtico dúrico (EKo), o que evidencia a maior participação de óxidos de Fe de pior cristalinidade cuja formação é favorecida pela restrição de drenagem, já que se localizam nas partes baixas da paisagem, onde é comum o acúmulo de água (Resende, 1976; Curi \& Franzmeier, 1984; Schwertmann, 1985; Filizola et al, 2001). Vale destacar que a presença de sílica no sistema inibe a expressão de formas de Fe de melhor cristalinidade (Schwertmann \& Taylor, 1989).

Observou-se, ainda, como tendência geral, maiores valores da relação Feo/Fed no horizonte A que no B, o que evidencia o efeito da matéria orgânica na inibição da cristalização dos óxidos de Fe, como sugere Schwertmann (1966).

Em todos os perfis analisados, com presença de horizonte coeso, os teores de $\mathrm{SiO}_{2}$ recuperados pelo DCB foram baixos (Quadro 1), sem que houvesse tendência de aumento nos horizontes endurecidos. Para Resende (1976), o DCB extrai a sílica associada aos óxidos de Fe. Por outro lado, segundo Smith \& Mitchell (1987), a sílica extraída pelo DCB está associada a filossilicatos que contêm Fe em sua estrutura, e que, nos solos estudados, teores baixos de Fe justificam os baixos teores de sílica recuperada com DCB. O Latossolo Vermelho (LVe), solo com maiores teores de $\mathrm{Fe}_{2} \mathrm{O}_{3}$, tanto do ditionito quanto do oxalato, foi o que apresentou valores de Sid mais elevados (Quadro1), sem que houvesse manifestação de endurecimento nos horizontes, o que parece confirmar as constatações feitas quanto à associação da sílica aos óxidos de Fe.

Observando a curva de Sid para os solos estudados e comparando-a com a de argila, percebe-se (Figura 1a, 1d, 2a, 3a) que esta não acompanhou a curva de argila, mantendo-se, praticamente, constante nos diversos horizontes, independentemente dos aumentos e, ou, diminuições nos teores de argila. Apenas no Argissolo Amarelo latossólico (Figura 3a), registrou-se discreto aumento no horizonte $\mathrm{Bt}_{1}$, que se manteve constante a maiores profundidades.

Quadro 1. Teores de $\mathrm{Fe}_{2} \mathrm{O}_{3}, \mathrm{SiO}_{2}$ e $\mathrm{Al}$ extraídos com DCB (ditionito-citrato-bicarbonato de sódio) e oxalato de amônio, teor de argila e valores de densidade do solo determinados em amostras de solos dos Tabuleiros Costeiros do Sul da Bahia

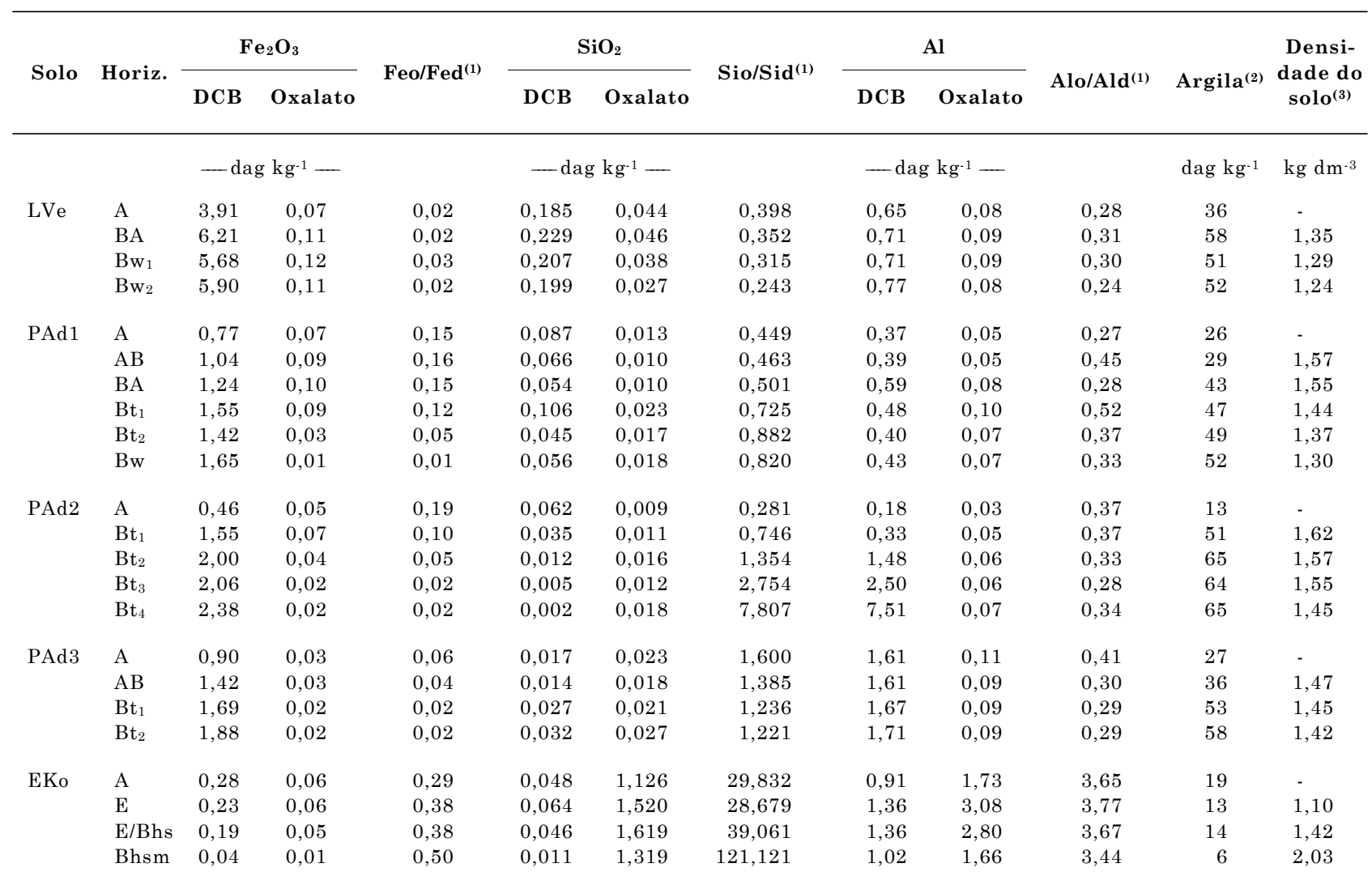

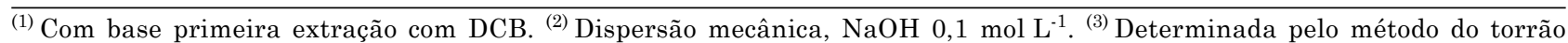
parafinado. 
O Argissolo Amarelo abrúptico (PAd2) apresentou algumas peculiaridades. $\mathrm{O}$ teor em argila neste solo aumentou 4,6 vezes do horizonte $\mathrm{A}$ em relação à parte coesa (horizontes $\mathrm{Bt}_{1}, \mathrm{Bt}_{2}, \mathrm{Bt}_{3}$ ); no entanto, a sílica do ditionito diminuiu 3,6 vezes e a do oxalato sofreu acréscimo de 1,44 vez (Quadro 1), estando ainda três vezes aquém do incremento em argila. Isso pode ser bem visualizado, comparando-se as curvas de Sio e Sid com as de argila deste solo (Figura 1b). Não se pode atribuir, portanto, a este ligeiro aumento no teor em sílica do oxalato a gênese do horizonte coeso, uma vez que se obteve correlação negativa e significativa $\left(\mathrm{r}=-0,99^{* * *}\right)$ para Sio/Sid e a densidade do solo, ou seja, à medida que aumentaram os valores desta relação e, conseqüentemente, os componentes amorfos, diminuiu a densidade do solo, sendo esta, portanto, uma variável que não explica a gênese da coesão. Ao que parece, o acréscimo observado na sílica extraída pelo oxalato (Quadro 1) provém da dissolução da caulinita, uma vez que os teores de Sio aumentam em profundidade, não refletindo, no entanto, manifestação do horizonte coeso.

Para o Espodossolo Cárbico órtico dúrico (EKo), os valores de sílica do oxalato foram bastante elevados (Quadro 1). A curva do Sio apresentou tendência oposta da curva de argila (Figura 2b). Enquanto esta última sofreu decréscimo do horizonte $\mathrm{A}$ em direção ao E, a curva de Sio seguiu tendência oposta, o que revela possível incremento por fluxo lateral decorrente da destruição da argila. Nos horizontes E e E/Bhsx, as duas curvas apresentaram o mesmo padrão de
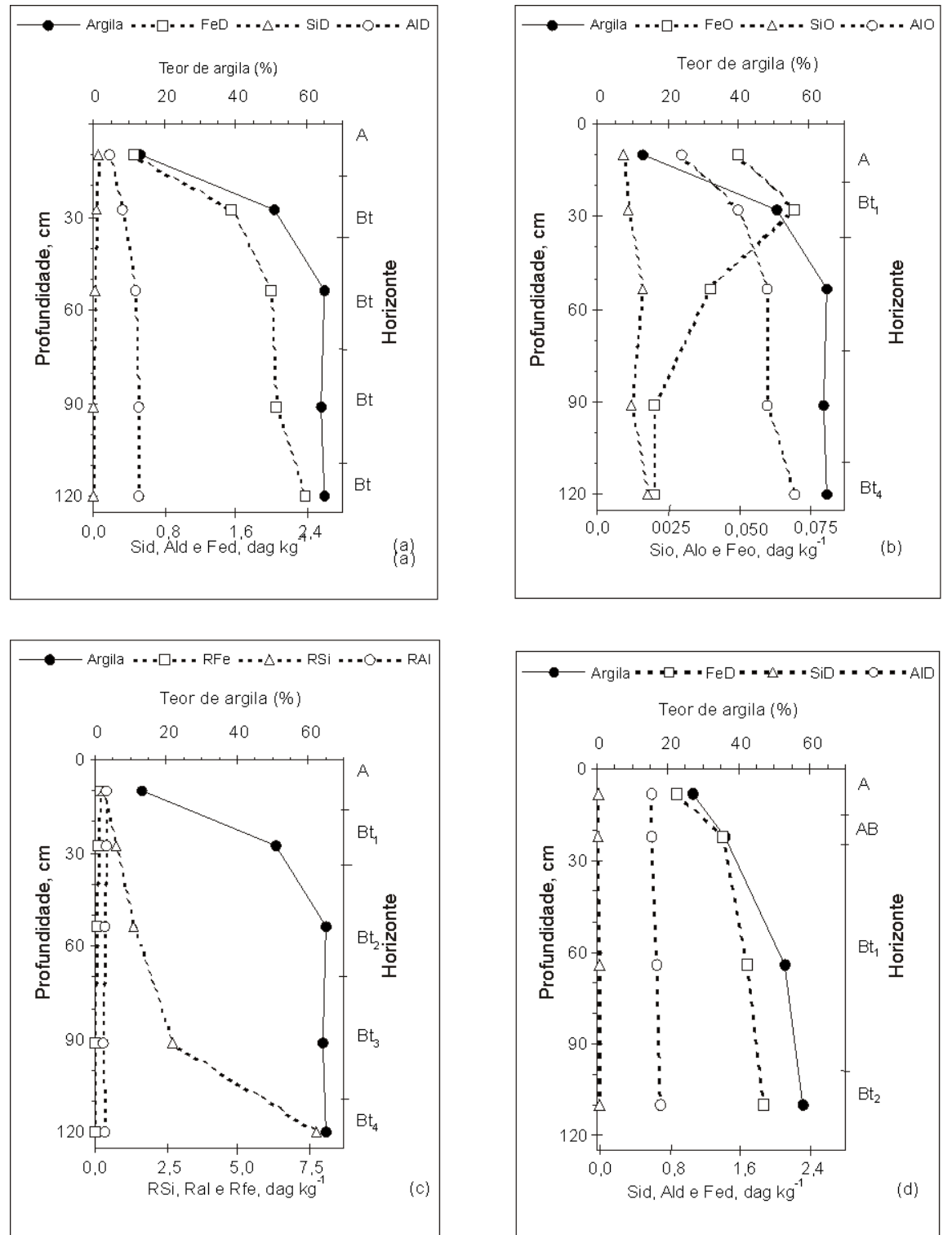

Figura 1. Curva do teor de argila e formas extraídas de $\mathrm{Si}$, $\mathrm{Al}$ e Fe com ditionito, oxalato e relações RSi (Sio/ Sid), RAl (Alo/Ald), RFe (Feo/Fed) em profundidade nos Argissolos Amarelos abrúpticos (a, b e c) e no típico (d). 

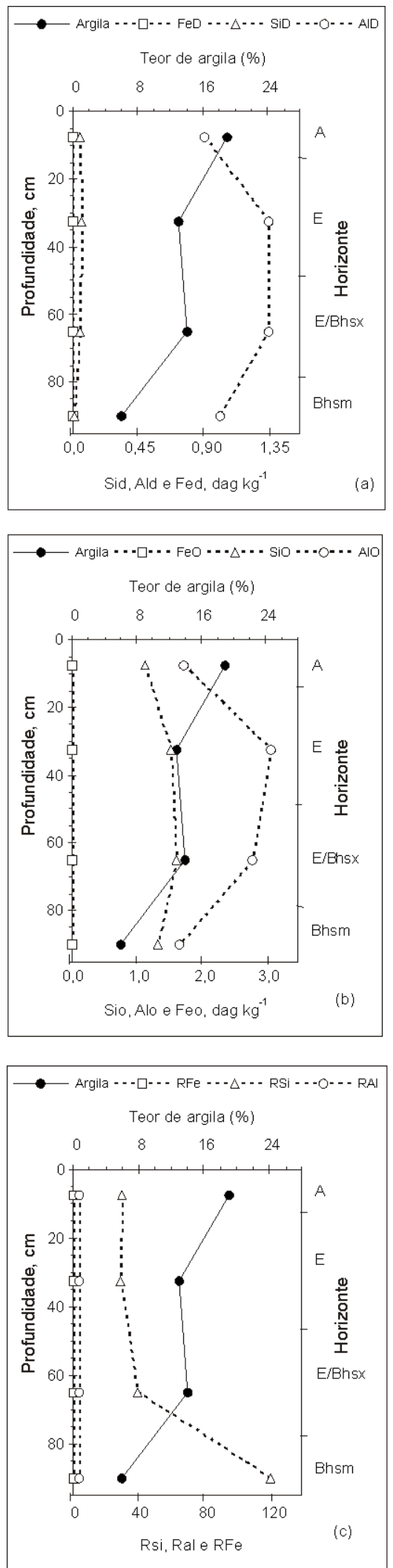

Figura 2. Curva do teor de Si, Al, e Fe argila e formas extraídas com ditionito (a), oxalato (b) e relações RSi (Sio/Sid), RAl (Alo/Ald), RFe (Feo/Fed) - (c) em profundidade no Espodossolo Cárbico órtico dúrico - EKo. comportamento e, no horizonte com duripã (Bhsm), observou-se, mais uma vez, que, apesar de os teores em argila diminuírem para mais da metade (Quadro 1), o da sílica sofreu ligeiro decréscimo de 1,2 vez, com maiores valores da relação Sio/Sid neste horizonte (Figura 2c), revelando a participação da sílica amorfa como agente cimentante no fragipã, conforme também observado por Steinhardt \& Franzmeier (1979); Karathanasis (1987); Rolim Neto \& Santos (1994); Filizola et al. (2001).

No EKo (Quadro 1), parte da sílica, proveniente, possivelmente, da ciclagem biológica e, ou, da dissolução da caulinita dos perfis localizados nas porções superiores da toposseqüência, deve estar combinada com o $\mathrm{Al}$, formando um aluminossilicato mal cristalizado, uma vez que as curvas de Sio e Alo apresentaram entre si comportamento semelhante nos horizontes A e E e contrário ao da curva de argila (Figura 3b). Segundo Mckeague \& Day (1966), esta forma de sílica é dissolvida, com mais eficiência, pelo oxalato e não pelo ditionito.

Exceto para o Eko, que apresentou relação Sio/Sid alta para todos os horizontes, nos demais solos, os valores desta relação foram baixos, tendendo a um aumento em profundidade (Quadro 1 e Figura 1c e 2c), o que pode ser devido à sílica proveniente da dissolução da caulinita.

Segundo Pedro \& Delmas (1979), em condições mais úmidas e meio ácido, a caulinita é dissolvida, sendo o $\mathrm{Al}$ da alteração da caulinita lixiviado do perfil, eventualmente pela ação complexante da matéria orgânica, permanecendo a sílica. Este fato parece justificar os maiores valores de Sio/Sid (Quadro 1), obtidos em maiores profundidades para os Argissolos Amarelos (PAd1 e PAd2), localizados nas áreas mais elevadas da paisagem, e valores mais baixos de Alo/ Ald (Quadro 1), nos mesmos horizontes, o que indica possível lixiviação de $\mathrm{Al}$ que tenderia a acumular-se nas áreas depressionais (EKo), onde foram encontrados maiores teores para estes óxidos (Quadro 1).

No Argissolo Amarelo latossólico (Figura 3b), a curva de Alo acompanhou a de argila até o horizonte BA, sofrendo acréscimo considerável no Bt1, apesar de o teor em argila manter-se constante. No entanto, mais uma vez, para o Espodossolo Cárbico órtico dúrico (EKo), os teores deste elemento foram bastante elevados com os dois extratores em todo o perfil, com tendências das curvas, tanto do Alo quanto do Ald, manterem-se opostas à curva de argila (Figura 2a e b). Neste solo, os horizontes acima do duripã apresentaram valores de Alo duas vezes maior que os valores obtidos para $\mathrm{Al}$ recuperado com ditionito. Resultados similares foram encontrados por Duncan \& Franzmeier (1999). Para eles, a maior parte do Al nos fragipãs encontra-se na estrutura dos óxidos de Fe, no entanto, nos horizontes superficiais a estes, o teor de $\mathrm{Al}$ é superior à capacidade dos óxidos de incorporá-lo, permanecendo na forma livre, sendo recuperados pelo oxalato. 

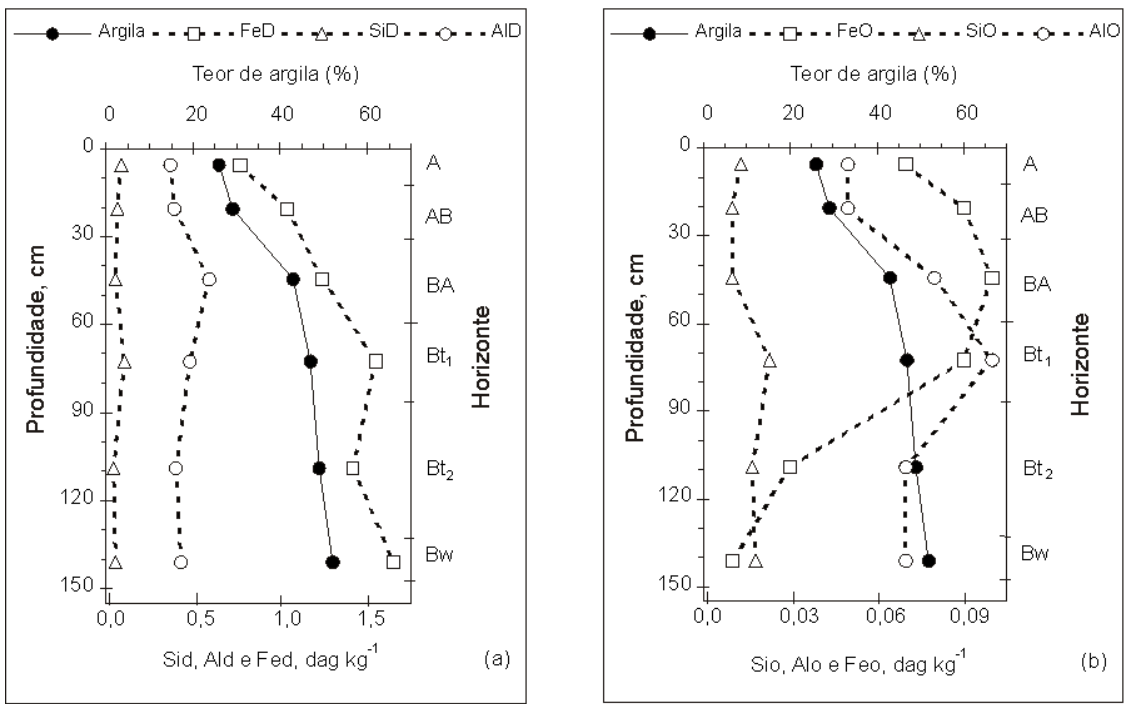

Figura 3. Curva do teor de argila e formas extraídas de Fe, Si e Al com ditionito (a) e oxalato (b) em profundidade no Argissolo Amarelo distrófico latossólico - PAd1.

Então, pode-se dizer que, no geral, os Argissolos Amarelos e Latossolo Vermelho apresentaram teores de $\mathrm{Al}$ e $\mathrm{Si}$ extraídos com ditionito maiores que os obtidos com o oxalato, estando associados às formas de melhor cristalinidade. Possivelmente, nos solos desenvolvidos de sedimentos do Grupo Barreiras, a alta concentração de $\mathrm{Al}$ na solução do solo favoreceu a substituição isomórfica do $\mathrm{Fe}$ pelo $\mathrm{Al}$ no processo de formação da goethita, como sugerido por Möller (1991), sendo este extraído com mais eficiência que a sílica pelo DCB.

Assim, para o Espodossolo Cárbico órtico dúrico (EKo), o oxalato foi mais eficiente que o ditionito na extração do $\mathrm{Al}$ e do $\mathrm{Si}$. O material amorfo extraído é formado, predominantemente, por $\mathrm{Al}$, com menor participação de minerais de $\mathrm{Fe}$, e a fração de $\mathrm{Si}$ removida encontra-se, possivelmente, associada ao $\mathrm{Al}$.

Os resultados obtidos indicam que a sílica e o $\mathrm{Al}$ desempenham papel relevante na gênese de fragipã $e$ duripã, e sua presença é determinante na manifestação da referida feição. Trabalhos como os de Anderson \& White (1958), Nettleton et al. (1968), Duncan \& Franzmeier (1999) contribuem com os resultados observados e, para os referidos autores, o material cimentante em fragipã e duripã parece ser um aluminossilicato solúvel em ditionito e oxalato que une os grãos do esqueleto do solo.

\section{Mineralogia do solo}

Os solos de tabuleiro apresentam a fração argila constituída, predominantemente, por caulinita e aparecem tanto nos horizontes superficiais quanto em maiores profundidades (Figuras 4 a 7), conforme constatado também por outros autores (Achá Panoso, 1976; Anjos, 1985).

A gibbsita foi identificada, e ao que tudo indica em pequena proporção, apenas nos horizontes $\mathrm{Bt}_{1}, \mathrm{Bt}_{2} \mathrm{e}$
Bw (Figura 4), livres de coesão e com estrutura fraca em blocos subangulares se desfazendo em moderada muito pequena granular, no Argissolo Amarelo distrófico latossólico (PAd1), e no Espodossolo Cárbico órtico dúrico (EKo), em toda a sua extensão (Figura 6).

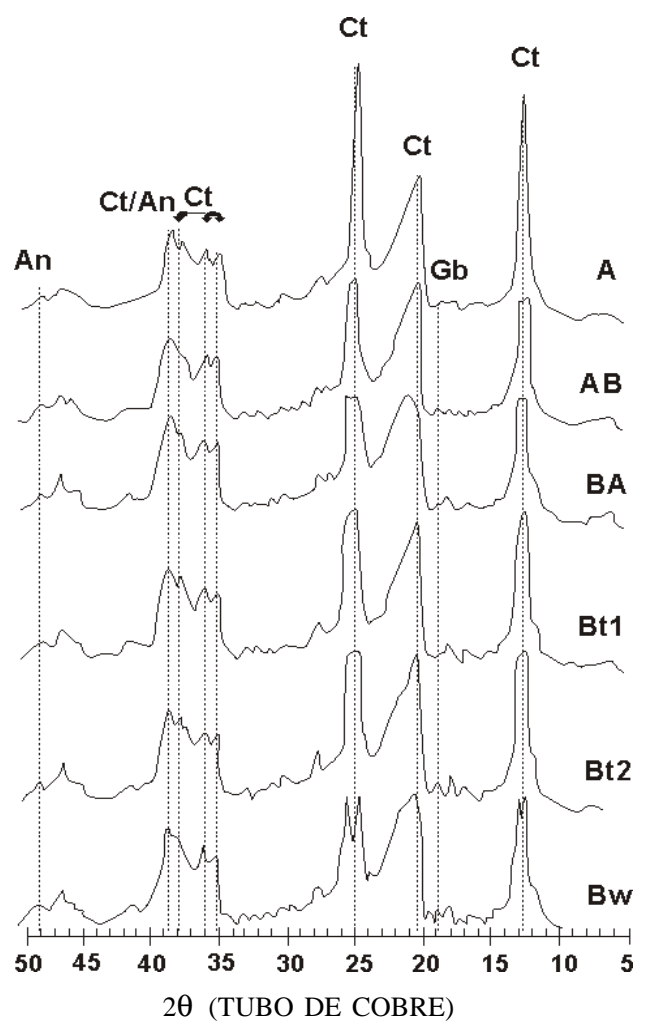

Figura 4. Difratogramas de raios-X da fração argila desferrificada do Argissolo Amarelo distrófico latossólico - PAd1(lâminas em pó). Ct - caulinita; Ct/An - caulinita/anatásio e An - anatásio. 


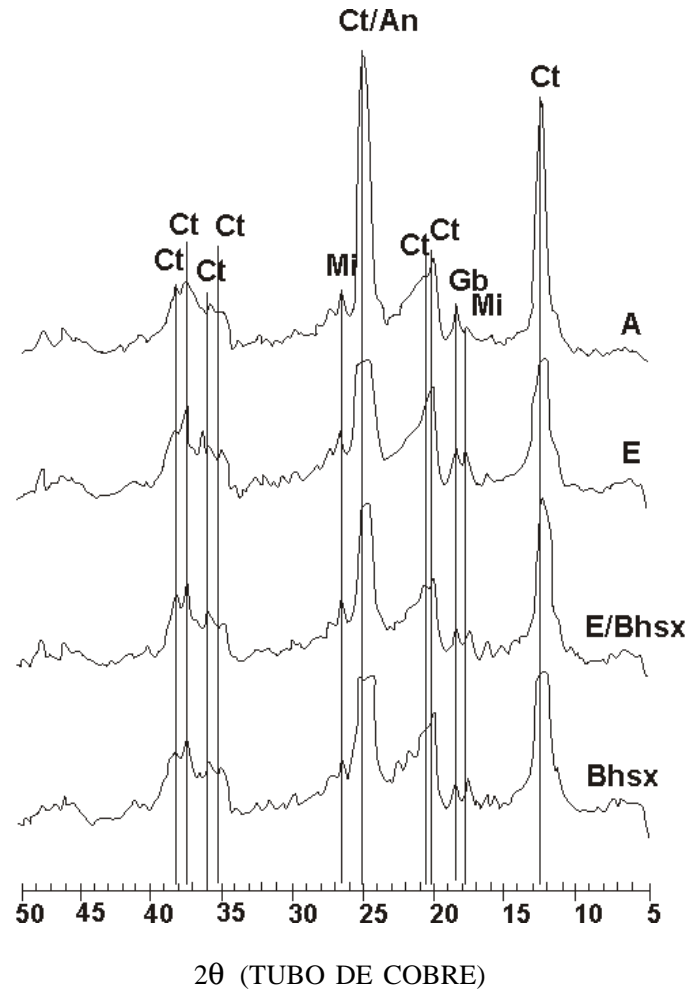

Figura 5. Difratogramas de raios-X da fração argila desferrificada do Argissolo Amarelo distrófico abrúptico - PAd2 (lâminas em pó). Ct - caulinita; Ct/An - caulinita/anatásio e An - anatásio.

Por outro lado, nos perfis de Argissolo PAd2 e PAd3 (Figuras 5 e 7), que apresentaram manifestação do caráter coeso mais pronunciado em toda a sua extensão, a gibbsita não foi identificada em nenhum horizonte. Com isso, confirma-se a hipótese da Univesidade Federal de Viçosa (1984), em que a gibbsita, quando presente no solo, dificulta o ajuste entre as lâminas de caulinita, impedindo, assim, a manifestação do caráter coeso, não havendo ainda relatos referentes à quantidade de gibbsita suficiente para tal efeito.

Fato curioso é que, no Espodossolo Cárbico órtico dúrico, a presença da gibbsita não impediu a manifestação de endurecimento, o que indica, mais uma vez, que os mecanismos diferem na formação de horizonte coeso, fragipã e duripã. Para o primeiro, mineralogia caulinítica e ausência de gibbsita são condições imprescindíveis, enquanto, nos dois últimos, o necessário é a presença de agente cimentante.

Portanto, os resultados da mineralogia da fração argila indicam que o tipo de mineral de argila não constituiu fator de diferenciação entre as três feições: horizonte coeso, fragipã e duripã, uma vez que a mineralogia dos solos estudados foi similar. Nos solos com o caráter coeso, a mineralogia essencialmente caulinítica e a sua forma placóide favorecem o ajuste cerrado entre as partículas de argila, indicando que o mecanismo de coesão é meramente físico e se desfaz

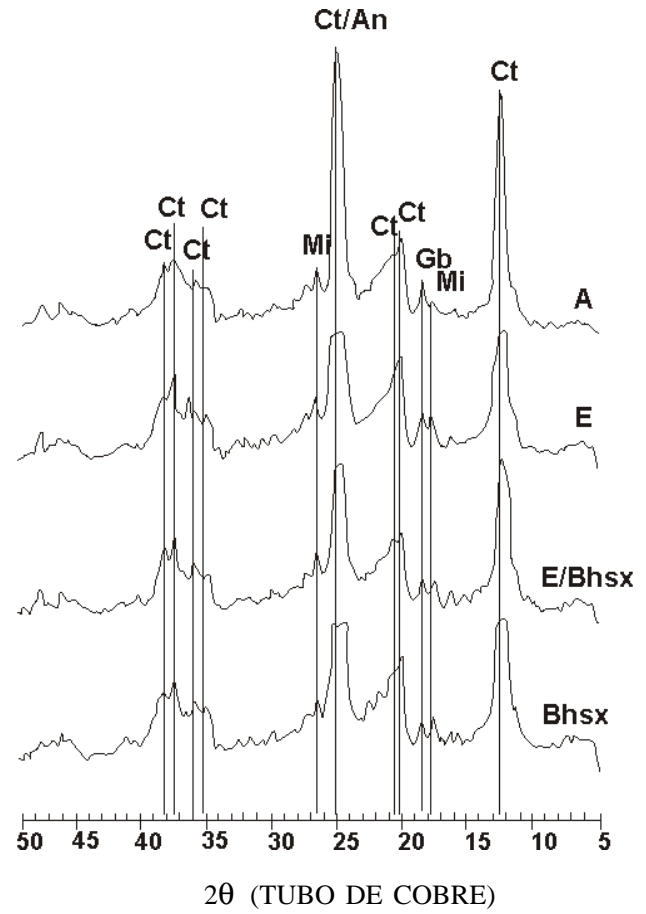

Figura 6. Difratogramas de raios-X da fração argila desferrificada do Espodossolo Cárbico órtico dúrico - EKo (lâminas em pó). Ct - caulinita; $\mathrm{Mi}$ mica; Gb - gibbsita; Ct/An - caulinita/anatásio e An - anatásio.

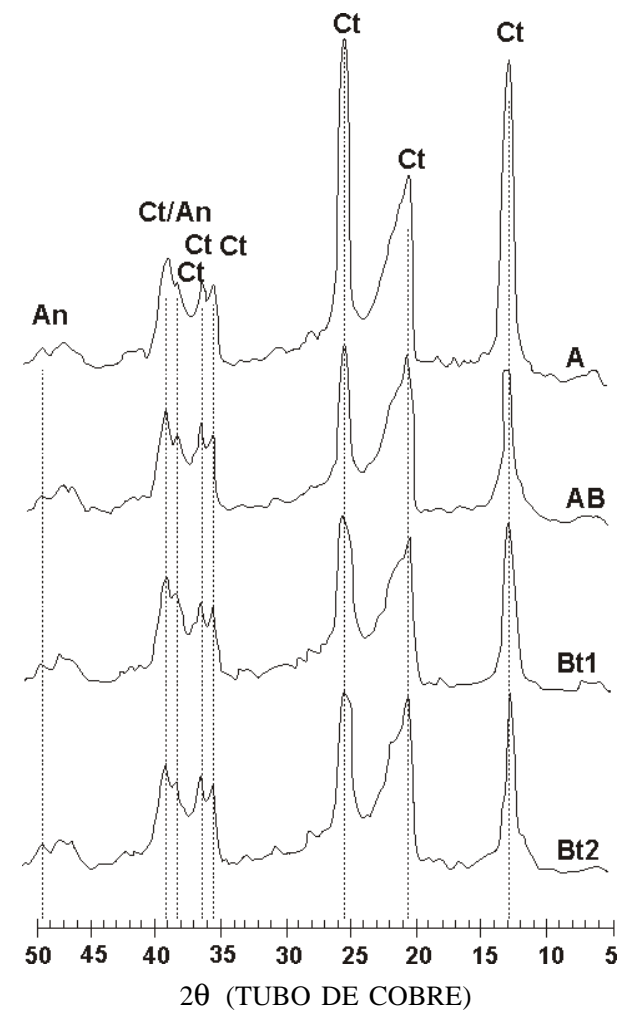

Figura 7. Difratogramas de raios-X da fração argila desferrificada do Argissolo Amarelo distrófico típico - PAd3 (lâminas em pó). Ct - caulinita; Ct/ An- caulinita/anatásio e An - anatásio. 
rapidamente com a umidade. No caso do Espodossolo Cárbico órtico dúrico, o ajuste entre as partículas do solo é intensificado pela presença de hidroxialuminossilicatos que funcionam como um cimento. Neste caso, em particular, a presença ou não de gibbsita parece não influenciar o processo, visto que o mecanismo é físico-químico e envolve adsorção de material amorfo como ligante entre as partículas.

Assim, para a formação de fragipã e duripã, o aspecto qualitativo da fração argila fica relegado a segundo plano. Segundo Petersen et al. (1970) e Richie et al. (1974), o que parece ser decisivo é o teor de argila, visto que, quando esse teor for superior a $35 \%$, sua formação é mais difícil, uma vez que, quando a área da superfície torna-se grande demais, a união efetiva entre as partículas por agentes cimentantes é dificultada, sendo as forças de expansão e contração mais fortes do que as de ligação (Smeck et al., 1989).

\section{CONCLUSÕES}

1. Para o Espodossolo Cárbico órtico dúrico, o oxalato foi mais eficiente que o ditionito na extração do $\mathrm{Al}$ e do Si. O material amorfo extraído é formado, predominantemente, por $\mathrm{Al}$, com menor participação de $\mathrm{Fe}$, e a fração de $\mathrm{Si}$ removida encontra-se, possivelmente, associada ao $\mathrm{Al}$.

2. Os teores de sílica e Al, extraídos tanto com o ditionito-citrato-bicarbonato quanto com o oxalato de amônio, foram baixos nos Argissolos Amarelos estudados, sem que houvesse tendência de aumento nos horizonte coesos.

3. Não se identificou a presença de gibbsita nos horizonte coesos estudados, apenas nos horizontes livres de coesão do Argissolo Amarelo latossólico, este óxido se fez presente.

\section{LITERATURA CITADA}

ACHÁ PANOSO, L. Latossolo Vermelho-Amarelo de "Tabuleiro" do Espírito Santo: Formação, características e classificação. Recife, Universidade Federal Rural de Pernanbuco, 1976. 116p. (Tese de Livre Docência)

ANDERSON, J.V. \& WHITE. J.L. A study of fragipans in some Southern Indiana soils. Soil Sci. Soc. Am . Proc., 22:450-454, 1958.

ANJOS, L.H.C. Caracterização, gênese, classificação e aptidão agrícola de uma seqüência de solos do Terciário na região de Campos-RJ. Itaguaí, Universidade Federal Rural do Rio de Janeiro, 1985. 194p. (Tese de Mestrado)

ARAÚJO FILHO, J.C.; CARVALHO, A. \& RODRIGUES E SILVA, F.B. Investigações preliminares sobre a pedogênese de horizontes coesos em solos dos tabuleiros costeiros do nordeste do Brasil. In: WORKSHOP COESÃO EM SOLOS DOS TABULEIROS COSTEIROS, Aracaju, 2001. Anais. Aracaju, Embrapa Tabuleiros Costeiros, 2001. 339p.
CURI, N. \& FRANZMEIER, D.P. Topossequence of Oxisol from the Central Plateau of Brazil. Soil Sci. Soc. Am. J., 48:341-346, 1984.

DUNCAN, M.M. \& FRANZMEIER, D.P. Role of free silicon, aluminum, and iron in fragipan formation. Soil Sci. Soc. Am. J., 63:923-929, 1999.

EMPRESA BRASILEIRA DE PESQUISA AGROPECUARIA EMBRAPA. Centro Nacional de Pesquisa de Solos. Sistema brasileiro de classificação de solos. Brasília, 1999. 412p.

FILIZOLA, H.F.; LAMOTTE, M.; FRITSCH, E.; BOULET, R.; ARAÚJO FILHO, J.C.; SILVA, F.B.R. \& LEPRUN, J.C. Os fragipãs e duripãs das depressões dos Tabuleiros Costeiros do nordeste brasileiro: Uma proposta de evolução. R. Bras. Ci. Solo, 25:947-964, 2001.

FONSECA, O.O.M. Caracterização e classificação de solos Latossólicos e Podzólicos desenvolvidos nos sedimentos do terciário no litoral Brasileiro. Itaguaí, Universidade Federal Rural do Rio de Janeiro, 1986. 185p. (Tese de Mestrado)

FRANZMEIER, D.P.; NORTON, L.D. \& STEINHARDT, G.C. Fragipans formation in loess of the Midwestern United States. In: SMECK, N.E. \& CIOLKOSZ, E.J., eds. Fragipans: Their occurrence, classification, and genesis. Wisconsin, USA. SSSA, 1989. p.69-97.

FRANZMEIER, D.P.; STEINHARDT, J.R. \& NORTON, L.D. Soil characterization in Indiana: I. field and laboratory procedures. West Lafayette, Purdue University, 1984. 30p.

GROSSMAN, R.B.\& CLINE, M.G. Fragipã horizons in New York soils. II. Relationships between rigidity and particle size distribution. Soil. Sci. Soc. Am. Proc., 21:322-325, 1957.

JACOMINE, P.K.T. Fragipãs em Solos de "Tabuleiros": Características, gênese e implicações no uso agrícola. Recife, Universidade Federal Rural de Pernambuco, 1974. 85p. (Tese de Livre Docência)

KARATHANASIS, A.D. Mineral solubility relationships in Fragiudalfs of Western Kentucky. Soil Sci. Soc. Am. J., 51:474-481, 1987.

LEMOS R.C. \& SANTOS, R.D. Manual de descrição e coleta de solo no campo. 3.ed. Campinas, Sociedade Brasileira de Ciência do Solo, 1996. 84p.

LIMA, H.V.; SILVA, A.P.; JACOMINE, P.K.T.; ROMERO, R.E. \& LIBARDI, P.L. Identificação e caracterização de solos coesos no Estado do Ceará. R. Bras. Ci. Solo, 28:467-476, 2004 .

McKEAGUE, J.A. \& DAY, J.H. Dithionite and oxalate extractable $\mathrm{Fe}$ and $\mathrm{Al}$ as aids in differentiating various classes of soil. Can. J. Soil Sci., 46:13-22, 1966.

MEHRA, J.P. \& JACKSON, M.L. Iron oxides removal from soils and clays by a dithionite-citrate-bicarbonate system buffered with sodium bicarbonate. Clays Clay Miner., 7:317-327, 1960.

MÖLLER, M.R.F. Substituição isomórfica de ferro de Latossolos da Amazônia e suas implicações na sorção de fósforo. Piracicaba, Escola Superior de Agricultura "Luiz de Queiroz", 1991. 70p. (Tese de Doutorado) 
NETTLETON, W.D.; McCRAKEN, R.J. \& DANIELS, R.B. Two North Carolina Coastal Plain catenas. II. Micromorphology, composition and fragipã genesis. Soil Sci. Soc. Am. Proc., 32:582-587, 1968.

NUNES, F.C.; RIBEIRO, L.P.; CUNHA, E.F. \& MAFRA, A.L. Gênese de solos coesos dos Tabuleiros Costeiros em uma toposseqüência no litoral norte da Bahia. In: CONGRESSO BRASILEIRO DE CIÊNCIA DO SOLO, 28., Ribeirão Preto, 2003. Anais. São Paulo, Sociedade Brasileira de Ciência do Solo, 2003. CD-ROM

PEDRO, G. \& DELMAS, A.B. Regards actuales sur les phénomènes dálteration hydrolitique. Leur nature, leur divérsité et leur place au cours de l'evolution géochimique superficielle. Cah. ORSTON, Sér. Pédologie, 18:217-234, 1979.

PETERSEN, G.W.; RANNEY. R.W.; CUNNINGHAM, R.L. \& MATELSKI R.P. Fragipans in Pennsylvania soils : A statistical study of laboratory data. Soil Sci. Soc. Am. Proc., 34:719-722. 1970.

RESENDE, M. Mineralogy, chemistry, morphology and geomorphology of some soils of the Central Plateau of Brazil. West Lafayette, Purdue University, 1976. 237p. (Tese de Doutorado)

RICHIE, A.; WILDING, L.P; HALL, G.F. \& STAHNKE, C.R. Genetic implications of B horizons in Aqualfs of Northeastern Ohio. Soil Sci. Soc. Am. J., 38:351-358, 1974.

RODRIGUES e SILVA, F.B. \& LEPRUN, J.C. Duripãs em solos dos Tabuleiros Costeiros do Nordeste do Brasil. In: CONGRESSO BRASILEIRO DE CIÊNCIA DO SOLO, 26., 1997, Rio de Janeiro, RJ. Anais. Local, Sociedade Brasileira de Ciência do Solo, 1997. CD-ROM

ROLIM NETO, F.C. \& SANTOS, M.D.C. Gênese de solo arenoso com lamelas e fragipã no agreste de Pernambuco. R. Bras. Ci. Solo, 18:243-253, 1994.
ROMERO, R.E.; CLEMENTE, C.A.; RIBEIRO, L.P.; MONTES, C.R. \& MELFI, A.J. Material cimentante de duripãs de uma toposseqüência dos Tabuleiros Costeiros. In: CONGRESSO BRASILEIRO DE CIÊNCIA DO SOLO, 28., Ribeirão Preto, 2003. Anais. São Paulo, Sociedade Brasileira de Ciência do Solo, 2003. CD-ROM

SCHWERTMANN, U. Inibitory effect of soil organic matter on the crystallization of amorphous ferric hidroxides. Nature, 212:645-646, 1966.

SCHWERTMANN, U. The effect of environments on iron oxide minerals. Adv. Soil Sci., 1:172-200, 1985.

SCHWERTMANN, U. \& TAYLOR, R.M. Iron oxides. In: DIXON, J.B. \& WEED, S.B., eds. Minerals in soil environments. Madison, Soil Science Society of America, 1989. p.379-438.

SMECK, N.E.; THOMPSON, M.L.; NORTON, L.D. \& SHIPITALO, M.J. Weathering discontinuities: A key to fragipan formation. In: SMECK N. E. \& CIOLKOSZ, E.J., eds. Fragipans: Their occurrence, classification, and genesis. Wisconsin, USA. SSSA, 1989. p.99-112.

SMITH, B.F.L. \& MITCHELL, B.D. Characterization of poorly ordered minerals by selective chemical methods. In: WILSON, M.J., ed. A handbook of determinative methods in clay mineralogy. London, Blackie \& Sons, 1987. p.275294.

STEINHARDT, G.C. \& FRANZMEIER, D.P. Chemical and mineralogical properties of the fragipans of the Cincinnati catena. Soil Sci. Soc. Am. J., 43:1008-1113, 1979

UNIVERSIDADE FEDERAL DE VIÇOSA - UFV. Caracterização de solos e avaliação dos principais sistemas de manejo dos tabuleiros costeiros do Baixo Rio Doce e das Regiões Norte do Estado do Espírito Santo e sua interpretação para uso agrícola. Viçosa, MG, Universidade Federal de Viçosa, 1984. 153p. (Relatório Convênio 545/81)

WINTERS, E. Silica hardpan development in the Red Yellow Podzolic soil region. Soil Sci. Am. Proc., 7:437-440, 1942.

WINTERS, E. \& SIMONSON, R.W. The sub-soil. In: NORMAN, A.G., ed. Advances in Agronomy. New York, Academic Press, 1951. p.1-92. 